\title{
Synthesis, spectral characterization and redox properties of iron (II) complexes of 1-alkyl-2-(arylazo)imidazole
}

\author{
U S RAY, D BANERJEE and C SINHA* \\ Department of Chemistry, The University of Burdwan, Burdwan 713 104, \\ India \\ e-mail: c_r_sinha@yahoo.com
}

MS received 26 February 2003; revised 12 May 2003

\begin{abstract}
Iron (II) complexes of 1-alkyl-2-(arylazo)imidazoles ( $p-\mathrm{R}_{-} \mathrm{C}_{6} \mathrm{H}_{4}-\mathrm{N}=\mathrm{N}$ $\mathrm{C}_{3} \mathrm{H}_{2} \mathrm{NN}-1-\mathrm{R}^{\prime}, \mathrm{R}=\mathrm{H}(\mathbf{a}), \mathrm{Me}(\mathbf{b}), \mathrm{Cl}(\mathbf{c})$ and $\mathrm{R}^{\prime}=\mathrm{Me}(\mathbf{1 / 3})$, Et $(\mathbf{2} / \mathbf{4})$ have been synthesized and formulated as tris-chelates $\mathrm{Fe}\left(\mathrm{RaaiR}^{\prime}\right)_{3}^{2+}$. They are characterized by microanalytical, conductance, UV-Vis, IR, magnetic (polycrystalline state) data. The complexes are low spin in character, $t_{2 g}^{6}$ (Fe(II)) configurations.
\end{abstract}

Keywords. Arylazoimidazole; Fe(II) complexes; tris-chelates.

\section{Introduction}

Arylazoheterocycles and their chemistry of transition and non-transition metals have been explored for more than two decades. ${ }^{1}$ Owing to their pH-response, photoactivity, light electron communication, stabilization of low valent metal oxidation state, exhibition of serial redox states of complexes, isolation of anion radicals, metal-ion specific solidphase extracting phenomena, anticancer medicine etc. different groups of researchers ${ }^{1-48}$ have tried to design newer azoheterocycles and their metal complexes and to explore their properties. We have also been engaged for the last few years in trying to enrich this field of chemistry.<smiles>[R]c1ccc(/N=N/c2nccn2[R])cc1</smiles>

$$
\text { RaaiR', } \begin{aligned}
\mathrm{R} & =\mathrm{H}(\mathbf{a}), \mathrm{Me}(\mathbf{b}), \mathrm{Cl}(\mathbf{c}) \\
\mathrm{R}^{\prime} & =\mathrm{Me}(\mathbf{1}), \mathrm{CH}_{2} \mathrm{CH}_{3}(\mathbf{2})
\end{aligned}
$$

We have designed two new classes of arylazoheterocycles: 1-alkyl-2-(arylazo)imidazoles $^{30-40}$ and 2-(arylazo)pyrimidines. ${ }^{41-44}$ Emphasis is laid on 2-(arylazo)imidazoles because of biological importance of imidazole $e^{49,50}$ and synthetic simplicity over other azoheterocycles. In continuation of our comprehensive studies on the coordinating

*For correspondence 
properties of 1-alkyl-2-(arylazo)imidazoles (RaaiR', 1) $\mathrm{R}^{\prime}=\mathrm{Me}(\mathbf{1})$, Et (2) this paper describes the synthesis, spectroscopic characterization and redox properties of a series of new iron(II) complexes.

\section{Experimental}

\subsection{Materials}

All reagents were of analytical grade and were used without further purification. 1-Alkyl2-(arylazo)imidazoles (RaaiR') were synthesized and characterized as per reported procedure. ${ }^{30,31}$ Solvents ( $\mathrm{MeOH}, \mathrm{MeCN}$ for electrochemistry) were purified by known methods. $^{32-34}$

\subsection{Analytical measurements}

Microanalytical data $(\mathrm{C}, \mathrm{H}, \mathrm{N})$ were collected using a Perkin-Elmer $2400 \mathrm{CHN}$ analyser. Iron analysis was carried out by AAS studies. ${ }^{51}$ Molar conductance of the complexes were recorded on a direct reading Systronic 304 model conductivity meter using $10^{-3} \mathrm{M}$ solutions. Magnetic susceptibilities were measured by the vibrating sample 155 magnetometer at $298 \mathrm{~K}$. IR and UV-Vis spectra were recorded on Jasco FTIR model 420 and Jasco UV/Vis/NIR model V-570 spectrophotometers. The electrochemistry of the complexes have been examined by cyclic voltammetry with EG and G PARC electrochemistry equipment at Pt-disk working electrode in $\mathrm{CH}_{2} \mathrm{Cl}_{2}-\mathrm{MeOH}(1: 1, v / v)$. Pt-wire auxiliary electrode and potentials are expressed with reference to the potential of SCE. Cyclic voltammograms of the complexes were drawn within the potential range +1.5 to $-1.5 \mathrm{~V}$ vs SCE.

\subsection{Synthesis of complexes}

Reaction condition has been set up following previously reported Fe(II)-complexes of 2(arylazo) pyridines. ${ }^{1}$ Synthesis of a representative complex is detailed below.

2.3a Iron (II) complexes, $\left[\mathrm{Fe}\left(\mathrm{RaaiR}^{\prime}\right)_{3}\right] I_{2}(\mathbf{3}, \mathbf{4})\left[\mathrm{Fe}\left(\mathrm{HaaiMe}_{3}\right] \mathrm{I}_{2}(\mathbf{3 a})\right.$ : An aqueous methanolic solution containing $\mathrm{FeSO}_{4}, 7 \mathrm{H}_{2} \mathrm{O}(0.07 \mathrm{~g}, 0.25 \mathrm{mmol})$ and HaaiMe $(0.14 \mathrm{~g}$, $0.75 \mathrm{mmol}$ ) was warmed and to this solution concentrated KI solution was added. The solution was stirred vigorously under $\mathrm{N}_{2}$ atmosphere for $3 \mathrm{~h}$ and cooled in a refrigerator to $5-10^{\circ} \mathrm{C}$; green crystals were deposited.

They were collected by filtration, washed with cold water, and $\mathrm{MeOH}$ and finally by $\mathrm{Et}_{2} \mathrm{O}$. It was dried in vacuo over $\mathrm{CaCl}_{2}$. Yield, $0 \cdot 15 \mathrm{~g}, 68 \%$.

All other complexes were prepared following identical procedure and the yield was varied from $65-70 \%$.

\section{Results and discussion}

\subsection{Synthesis and formulation}

The ligands, RaaiR', belong to the unsymmetric $\mathrm{N}, \mathrm{N}^{\prime}$-chelating system. The donor centres $\mathrm{N}\left(\right.$ imidazole) and $\mathrm{N}($ azo $)$ are denoted by $\mathrm{N}$ and $\mathrm{N}^{\prime}$ respectively. From an aqueous 
solution of $\mathrm{FeSO}_{4} \cdot 7 \mathrm{H}_{2} \mathrm{O}$ and $\mathrm{RaaiR}^{\prime}$ in methanol in $1: 3$ mole ratio in presence of excess of $\mathrm{KI}$, we have isolated green coloured crystalline products of composition $\left[\mathrm{Fe}\left(\mathrm{RaaiR}^{\prime}\right)_{3}\right] \mathrm{I}_{2}(\mathbf{3 , 4})$. Addition of saturated solution of $\mathrm{NaClO}_{4} / \mathrm{NH}_{4} \mathrm{PF}_{6}$ also affords complexes of the same composition $\left[\mathrm{Fe}\left(\mathrm{RaaiR}^{\prime}\right)_{3}\right]\left[\left(\mathrm{ClO}_{4}\right)_{2} /\left(\mathrm{PF}_{6}\right)_{2}\right]$. The perchlorate salts, $\left[\mathrm{Fe}\left(\mathrm{RaaiR}^{\prime}\right)_{3}\right]\left(\mathrm{ClO}_{4}\right)_{2}$ are relatively less stable in solution and slowly change from green to orange yellow compared to $\mathrm{PF}_{6}^{-}$and $\mathrm{I}^{-}$salts. The commercially available $\mathrm{PF}_{6}$-salts, $\mathrm{NH}_{4} \mathrm{PF}_{6} / \mathrm{KPF}_{6}$ are expensive, hence we have examined the properties of complexes with iodide salts, $\left[\mathrm{Fe}\left(\mathrm{RaaiR}^{\prime}\right)_{3}\right] \mathrm{I}_{2}$. Microanalytical data support the composition of the complexes. The molar conductance measurement $\left(\Lambda_{\mathrm{M}}=140-170 \Omega^{-1} \mathrm{~cm}^{-1}\right)$ suggests $1: 2$ electrolyte nature of the complexes. The complexes are diamagnetic and support low spin $t_{2 g}^{6}$ electronic configuration.

\subsection{IR spectra}

The most plausible assignments of the IR bands useful for establishing the coordination modes of the title complexes have been compared with free ligand values. ${ }^{37}$ The most significant difference has been observed in the azoimine function. The $v(\mathrm{C}=\mathrm{N})$ and $v(\mathrm{~N}=\mathrm{N})$ appear at $1580-1600$ and $1380-1390 \mathrm{~cm}^{-1}$ in $\mathrm{Fe}(\mathrm{II})$-complexes and are shifted to lower frequency by $20-50 \mathrm{~cm}^{-1}$ compared to free ligand values. ${ }^{30,31}$ This is in support of the $\pi$-acidic character of the azoimine group, while Fe(II) shows $\pi$-back donation. This is common with complexes of azoimidazoles in higher congeners of group VIII, ruthenium and osmium, of iron. ${ }^{32-36} v(\mathrm{Fe}-\mathrm{N})$ may appear at $320-330 \mathrm{~cm}^{-1}$ which is absent in the free ligand spectra.

\subsection{Absorption spectra}

UV-Vis spectral studies of the complexes exhibit transition at lower than $400 \mathrm{~nm}$ corresponding to intramolecular $n \rightarrow \pi^{*}$ and $\pi \rightarrow \pi^{*}$ charge transfer transitions (table 1). Intense absorption bands $\left(\varepsilon \sim 10^{4}\right)$ appear in the range $420-455$ for the complexes which may be assigned to $d(\mathrm{Fe}) \rightarrow \pi^{*}$ (ligand) charge transfer transitions. A broad weak band $\left(\varepsilon=270-700 \mathrm{M}^{-1} \mathrm{~cm}^{-1}\right)$ is observed at $620-690 \mathrm{~nm}$.

\subsection{Cyclic voltammetry}

Cyclic voltammetric data are given in table 2 . $\left[\mathrm{Fe}\left(\mathrm{RaaiR}^{\prime}\right)_{3}\right] \mathrm{I}_{2}$ shows two redox responses at positive to SCE. One of them at higher positive potential $\left(E_{1 / 2}^{\mathrm{M}}=0 \cdot 8-0.9 \mathrm{~V}\right.$ vs SCE $)$ exhibits cathodic peak on scan reversal while the second response at lower potential $\left(E_{p c}\right.$ $0.6 \mathrm{~V}$ ) does not show reasonable $E_{p c}$ on scan reversal (figure 1). The quasireversibility of voltammogram at $0.8-0.9 \mathrm{~V}$ is reflected in peak-to-peak separation $\left(\Delta E_{p}>120 \mathrm{mV}\right)$. There are two redox active centres that may be oxidized: they are $\mathrm{Fe}(\mathrm{II})$ and $\mathrm{I}^{-}$. To assign the redox responses we draw a cyclic voltammogram of $\left[\mathrm{Fe}(\mathrm{MeaaiMe})_{3}\right]\left(\mathrm{PF}_{6}\right)_{2}$ under identical experimental condition which does not show anodic response at $0.6 \mathrm{~V}$ and shows only quasireversible redox couple at $0 \cdot 8-0.9 \mathrm{~V}$. The latter couple has been assigned to the $\mathrm{Fe}(\mathrm{III}) / \mathrm{Fe}$ (II) couple (1), and the $E_{P a}$ at $0.6 \mathrm{~V}$ corresponds to $1 / \mathbf{L}_{2} / \mathrm{I}^{-}$reaction (2).

$$
\begin{aligned}
& {\left[\mathrm{Fe}\left(\text { RaaiR }^{\prime}\right)_{3}\right]^{3+}+e \rightleftharpoons\left[\mathrm{Fe}\left(\text { RaaiR }^{\prime}\right)_{3}\right]^{2+},} \\
& 1 / 2 \mathrm{I}_{2}+e \rightarrow \mathrm{I}^{-} .
\end{aligned}
$$


Table 1. Microanalytical ${ }^{\mathrm{a}}$ and UV-Vis ${ }^{\mathrm{b}}$ spectra data.

\begin{tabular}{|c|c|c|c|c|c|}
\hline \multirow[b]{2}{*}{ Compound } & \multicolumn{4}{|c|}{ Found (calcd.) (\%) } & \multirow[b]{2}{*}{$\lambda_{\max } / \mathrm{nm}\left(10^{-3} \varepsilon / \mathrm{dm}^{3} \mathrm{~mol}^{-1} \mathrm{~cm}^{-1}\right)$} \\
\hline & $\mathrm{C}$ & $\mathrm{H}$ & $\mathrm{N}$ & $\mathrm{Fe}$ & \\
\hline$\left[\mathrm{Fe}(\text { HaaiMe })_{3}\right] \mathrm{I}_{2}(\mathbf{3 a})$ & $\begin{array}{c}41 \cdot 51 \\
(41 \cdot 48)\end{array}$ & $\begin{array}{c}3.48 \\
(3 \cdot 45)\end{array}$ & $\begin{array}{c}19 \cdot 41 \\
(19 \cdot 36)\end{array}$ & $\begin{array}{l}6 \cdot 7 \\
(6 \cdot 43)\end{array}$ & $\begin{array}{l}622(0.708), 422(6.82)^{\mathrm{c}} \\
358(8.768), 302(9 \cdot 388) \\
226(17.98)\end{array}$ \\
\hline$\left[\mathrm{Fe}(\text { MeaaiMe })_{3}\right] \mathrm{I}_{2}(\mathbf{3 b})$ & $\begin{array}{c}43.43 \\
(43.53)\end{array}$ & $\begin{array}{c}3 \cdot 52 \\
(3 \cdot 95)\end{array}$ & $\begin{array}{c}18 \cdot 24 \\
(18 \cdot 46)\end{array}$ & $\begin{array}{c}6 \cdot 18 \\
(6 \cdot 13)\end{array}$ & $\begin{array}{l}626(0 \cdot 518), 420(9 \cdot 35)^{\mathrm{c}} \\
384(12 \cdot 78)^{\mathrm{c}}, 354(11 \cdot 00) \\
294(7 \cdot 07), 234(12 \cdot 86)\end{array}$ \\
\hline$\left[\mathrm{Fe}(\text { ClaaiMe })_{3}\right] \mathrm{I}_{2}(\mathbf{3 c})$ & $\begin{array}{c}37 \cdot 12 \\
(37 \cdot 01)\end{array}$ & $\begin{array}{c}2 \cdot 98 \\
(2 \cdot 77)\end{array}$ & $\begin{array}{c}17 \cdot 47 \\
(17 \cdot 27)\end{array}$ & $\begin{array}{c}5 \cdot 92 \\
(5 \cdot 74)\end{array}$ & $\begin{array}{l}690(0.586), 418(9.265)^{\mathrm{c}} \\
378(3.516)^{\mathrm{c}}, 368(35.56) \\
284(4.96)^{\mathrm{c}}, 242(13.65)^{\mathrm{c}}\end{array}$ \\
\hline$\left[\mathrm{Fe}(\mathrm{HaaiEt})_{3}\right] \mathrm{I}_{2}(\mathbf{4 a})$ & $\begin{array}{c}43 \cdot 24 \\
(43 \cdot 53)\end{array}$ & $\begin{array}{l}4 \cdot 1 \\
(3 \cdot 96)\end{array}$ & $\begin{array}{c}18 \cdot 35 \\
(18 \cdot 47)\end{array}$ & $\begin{array}{c}6 \cdot 15 \\
(6 \cdot 13)\end{array}$ & $\begin{array}{l}624(3 \cdot 89), 446(3 \cdot 17) \\
420(5 \cdot 85)^{\mathrm{c}}, 374(11 \cdot 56) \\
294(8 \cdot 426)\end{array}$ \\
\hline$\left[\mathrm{Fe}(\text { MeaaiEt })_{3}\right] \mathrm{I}_{2}(\mathbf{4 b})$ & $\begin{array}{c}45 \cdot 18 \\
(45 \cdot 39)\end{array}$ & $\begin{array}{c}4 \cdot 12 \\
(4 \cdot 41)\end{array}$ & $\begin{array}{c}17 \cdot 74 \\
(17 \cdot 65)\end{array}$ & $\begin{array}{c}6 \cdot 1 \\
(5 \cdot 86)\end{array}$ & $\begin{array}{l}624(3.374), 424(7.51)^{\mathrm{c}} \\
380(12 \cdot 712), 374(12 \cdot 651) \\
294(6 \cdot 537)\end{array}$ \\
\hline$\left[\mathrm{Fe}(\mathrm{ClaaiEt})_{3}\right] \mathrm{I}_{2}(\mathbf{4 c})$ & $\begin{array}{c}39 \cdot 11 \\
(39 \cdot 02)\end{array}$ & $\begin{array}{c}3 \cdot 41 \\
(3 \cdot 25)\end{array}$ & $\begin{array}{c}16 \cdot 71 \\
(16 \cdot 56)\end{array}$ & $\begin{array}{l}5 \cdot 7 \\
(5 \cdot 50)\end{array}$ & $\begin{array}{l}643(0 \cdot 265), 450(4 \cdot 54), \\
382(42 \cdot 53)^{\mathrm{c}}, 372(43 \cdot 79), \\
288(6 \cdot 507)^{\mathrm{c}}, 242(13 \cdot 93), \\
226(20 \cdot 617)\end{array}$ \\
\hline
\end{tabular}

${ }^{\mathrm{a}}$ Calculated values are in parentheses; ${ }^{\mathrm{b}}$ solvent $\mathrm{MeCN} ;{ }^{\mathrm{c}}$ shoulder

Table 2. Cyclic voltammetric ${ }^{\text {a }}$ data.

\begin{tabular}{lccc}
\hline Compound & $E_{1 / 2}[\mathrm{Fe}(\mathrm{III}) / \mathrm{Fe}(\mathrm{II})](\mathrm{V})\left(\Delta E_{p}, \mathrm{mV}\right)$ & \multicolumn{2}{c}{ Ligand reductions $(\mathrm{V})$} \\
\hline$\left[\mathrm{Fe}(\text { HaaiMe })_{3}\right] \mathrm{I}_{2}(\mathbf{3 a})$ & $0.878(120)$ & $-0.40(110),-0.73(120)$ & $-1.18(160)$ \\
{$\left[\mathrm{Fe}(\mathrm{MeaaiMe})_{3}\right] \mathrm{I}_{2}(\mathbf{3 b})$} & $0.815(125)$ & $-0.48(110),-0.81(130)$ & $-1.26(140)$ \\
{$\left[\mathrm{Fe}(\text { ClaaiMe })_{3}\right] \mathrm{I}_{2}(\mathbf{3 c})$} & $0.805(75)$ & $-0.70(140),-0.40(130)$ & $-1.10(175)$ \\
{$\left[\mathrm{Fe}(\mathrm{HaaiEt})_{3}\right] \mathrm{I}_{2}(\mathbf{4 a})$} & $0.842(85)$ & $-0.44(130),-0.78(140)$ & $-0.916(130)$ \\
{$\left[\mathrm{Fe}(\text { MeaaiEt })_{3}\right] \mathrm{I}_{2}(\mathbf{4 b})$} & $0.788(80)$ & $-0.52(130),-0.88(140)$ & $-1.38(165)$ \\
{$\left[\mathrm{Fe}(\text { ClaaiEt })_{3}\right] \mathrm{I}_{2}(\mathbf{4 c})$} & $0.896(90)$ & $-0.42(120),-0.75(125)$ & $-1.13(140)$ \\
\hline
\end{tabular}

${ }^{\text {a }}$ Solvent $\mathrm{MeCN}$; Pt-disk working electrode for 3, 4; reference SCE; supporting electrolyte $\left[\mathrm{Bu}_{4} \mathrm{~N}\right]\left[\mathrm{ClO}_{4}\right] . E_{1 / 2}=0.5\left(E p_{a}+E p_{c}\right), \mathrm{V} ; \Delta E_{p}=\left(E p_{a}-E p_{c}\right), \mathrm{mV}, E_{p a}=$ anodic peak potential; $E_{p c}=$ cathodic peak potential

Owing to charge transfer between $\mathrm{I}^{-}$and $\left[\mathrm{Fe}\left(\mathrm{RaaiR}^{\prime}\right)_{3}\right]^{2+}$ in the ionic association and solvation effect, $1 / 2 \mathrm{I}_{2} / \mathrm{I}^{-}$oxidation couple may be shifted to higher potential values compared to standard reported potential values. ${ }^{54}$ The one-electron nature of the redox process in (1) is supported by the $i_{P a} / i_{P C}\left(i_{P a}=\right.$ anodic peak current and $i_{P C}=$ cathodic peak current) which varies from $0.9-1.05$ and on the comparing current height of $\left[\mathrm{Fe}(\mathrm{CN})_{6}\right]^{3-}$ / $\left[\mathrm{Fe}(\mathrm{CN})_{6}\right]^{4-}$ couple.

There are three redox couples that appear at negative values to SCE and are due to reductions of the ligand (figure 1). Arylazoimidazoles usually accommodate two electrons at LUMO which is mostly azo in character. These three redox responses are due to $\mathrm{azo}^{-} / \mathrm{azo}$ redox reaction of three-coordinated RaaiR ${ }^{\prime 32-36}$ Other three reductions were not observable because of 


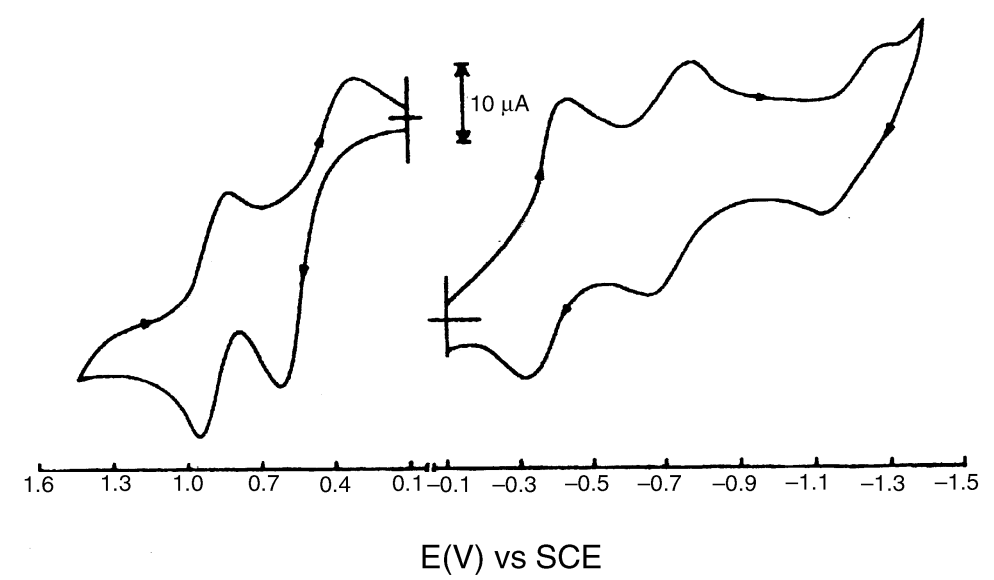

Figure 1. Cyclic voltammogram of $\left[\mathrm{Fe}(\mathrm{HaaiMe})_{3}\right] \mathrm{I}_{2}$ (3a) in $\mathrm{MeCN}$.

$$
\begin{aligned}
& {\left[\mathrm{Fe}\left(\operatorname{RaaiR}^{\prime}\right)_{3}\right]^{2+}+e \rightleftharpoons\left[\mathrm{Fe}(\operatorname{RaaiR})_{2}\left(\operatorname{RaaiR}^{\prime}\right)\right]^{+},} \\
& {\left[\mathrm{Fe}\left(\operatorname{RaaiR}^{\prime}\right)_{2}\left(\operatorname{RaaiR}^{\prime-}\right)\right]^{+}+e \rightleftharpoons\left[\mathrm{Fe}\left(\operatorname{RaaiR}^{\prime}\right)\left(\operatorname{RaaiR}^{\prime-}\right)_{2}\right],} \\
& {\left[\mathrm{Fe}\left(\operatorname{RaaiR}^{\prime}\right)\left(\operatorname{RaaiR}^{\prime-}\right)_{2}\right]+e \rightleftharpoons\left[\mathrm{Fe}\left(\operatorname{RaaiR}^{\prime-}\right)_{3}\right]^{-} .}
\end{aligned}
$$

The solvent cut-off region appears near $-1.5 \mathrm{~V}$. They certainly need more negative potential since electron are accommodated at SOMO which feels repulsion by incoming electron(s). Redox couples are systematically affected by substituents $\mathrm{R}$ and are linearly related to the Hammett $\sigma$.

\section{Conclusions}

This work describes the coordination chemistry of iron(II) with the 1-alkyl-2(arylazo)imidazole ligand which contains the azoimine $(-\mathrm{N}=\mathrm{N}-\mathrm{C}=\mathrm{N}-)$ function. The complexes have been synthesized and characterized by microanalytical, spectral, electrochemical and magnetic study.

\section{Acknowledgement}

Financial support from the University Grants Commission (UGC) is gratefully acknowledged. One of us (UR) thanks the UGC for a fellowship.

\section{References}

1. Raghavendra B S and Chakravorty A 1976 Inorg. Chim. Acta. A14 166

2. Krause R A and Krause K 1980 Inorg. Chem. 192600

3. Krause R A and Krause K 1982 Inorg. Chem. 211714

4. Ferreira V and Krause R A 1988 Inorg. Chim. Acta 14529

5. Goswami S, Chakravarty A R and Chakravorty A 1981 Inorg. Chem. 202246

6. Goswami S, Chakravarty A R and Chakravorty A 1982 Inorg. Chem. 212737

7. Goswami S, Chakravarty A R and Chakravorty A 1983 Inorg. Chem. 22602

8. Goswami S, Mukherjee R and Chakravorty A 1983 Inorg. Chem. 222825

9. Datta D and Chakravorty A 1983 Inorg. Chem. 221085

10. Ghosh B K and Chakravorty A 1989 Coord. Chem. Rev. 95239 
11. Moreno J M, Ruiz J, Domingnez-Vera J M, Colacio E, Galisto D and Kivekas R 1994 Polyhedron 13203

12. Hayami S, Inone K, Osaki S and Maeda Y 1998 Chem. Lett. 987

13. Au Y-K, Cheung K-K and Wong W-T 1995 Inorg. Chim. Acta 238193

14. Hartmann H, Scheiring T, Fielder J and Kaim W 2000 J. Organomet. Chem. 604267

15. Fees J, Hausen H-D and Kaim W 1995 Z. Naturoforsch. B50 15

16. Pramanik K, Shivakumar M, Ghosh P and Chakravorty A 2000 Inorg. Chem. 39195

17. Shivakumar M, Pramanik K, Bhattacharyya I and Chakravorty A 2000 Inorg. Chem. 394332

18. Shivakumar M, Gangopadhyay J and Chakravorty A 2001 Polyhedron 202089

19. Hotze A C G, Broekhuisen M E T, Velders A H, Vander Schilden K, Haasnoot J G and Reedijk J 2002 Eur. J. Inorg. Chem. 369

20. Saha A, Majumdar P, Peng S-M and Goswami S 2000 Eur. J. Inorg. Chem. 2631

21. Das C, Peng S-M, Lee G H and Goswami S 2002 New J. Chem. 26222

22. Mondal B, Paul H, Puranik P G and Lahiri G K 2001 J. Chem. Soc., Dalton Trans. 481

23. Pramanik N C, Pramanik K, Ghosh P and Bhattacharyya S 1998 Polyhedron 171525

24. Bhattacharyya S, Chakraborty I, Dirghangi B K and Chakravorty A 2000 Chem. Commun. 1813

25. Bhattacharyya S, Chakraborty I, Dirghangi B K and Chakravorty A 2001 Inorg. Chem. 40286

26. Ghosh B K, Mukhopadhyay A, Goswami S, Ray S and Chakravorty A 1984 Inorg. Chem. 23 4633

27. Das A, Peng S-M and Bhattacharyya S 2000 Polyhedron 191227

28. Santra B K and Lahiri G K 1997 J. Chem. Soc., Dalton Trans. 129

29. Santra B K, Munshi P, Das G, Bharadwaj P and Lahiri G K 1999 Polyhedron 18617

30. Misra T K, Das D and Sinha C 1997 Polyhedron 164163

31. Das D, Misra T K and Sinha C 1998 Transition Met. Chem. 2373

32. Misra T K, Das D, Sinha C, Ghosh P K and Pal C K 1998 Inorg. Chem. 371672

33. Misra T K and Sinha C 1999 Transition Met. Chem. 24172

34. Pal S, Misra T K and Sinha C 2000 Transition Met. Chem. 25333

35. Pal S, Misra T K, Chattopadhyay P and Sinha C 1999 Proc. Indian Acad. Sci. (Chem. Sci.) 111687

36. Byabartta P, Pal S, Misra T K, Sinha C, Liao F-L, Pannerselvam K and Lu T-H $2002 J$. Coord. Chem. $\mathbf{5 5} 479$

37. Das D and Sinha C 1998 Transition Met. Chem. 23517

38. Pal S, Das D, Sinha C and Kennard C H L 2001 Inorg. Chim. Acta 31321

39. Rauth G K, Pal S, Das D and Sinha C 2001 Transition Met. Chem. 26679

40. Das D, Das A K and Sinha C 1999 Anal. Lett. 32 567; Das D, Das A K and Sinha C 1999 Talanta 481013

41. Santra P K, Das D, Misra T K, Roy R, Sinha C and Peng S-M 1999 Polyhedron 181909

42. Santra P K, Misra T K, Das D, Sinha C, Slawin A M Z and Woollins J D 1999 Polyhedron 18 2869

43. Santra P K, Sinha C, Sheen W-J, Liao F-L and Lu T-H 2001 Polyhedron 20599

44. Senapoti S, Ray U S, Santra P K, Sinha C, Woollins J D and Slawin A M Z 2002 Polyhedron 21753

45. Akasaka T, Otsuki J and Araki K 2002 Chem. Eur. J. 130

46. Camalli M, Caruso F, Mattogno G and Rivarola E 1990 Inorg. Chim. Acta 170225

47. Nag J K, Santra P K, Sinha C, Liao F-L and Lu T-H 2001 Polyhedron 202253

48. Bag K, De N K, De B B and Sinha C 1997 Proc. Indian Acad. Sci. (Chem. Sci.) 109159

49. Rypniewski W R, Managani S, Bruni S, Orioli P L, Casati M and Wilson K 1995 J. Mol. Biol. 251282

50. Wang L, Bailly C, Kumar A, Ding D, Bajic M and Wilson W D 2002 Proc. Natl. Acad. Sci. USA 9712

51. Вað H, Trker A R, Tunceli A and Lale M 2001 Anal. Sci. 17901

52. Byabartta P, Dinda J, Santra P K, Sinha C, Pannerselvam K, Liao F-L and Lu T-H $2001 J$. Chem. Soc., Dalton Trans. 2825

53. Bera P, Saha N, Kumar S, Banerjee D and Bhattacharya R 1999 Transition Met. Chem. 24425

54. Rubinson J F, Rubinson K A 1998 Contemporary chemical analysis (Englewood Cliffs, NJ: Prentice Hall) 